\title{
RESPOSTAS FOTOSSINTÉTICAS DO CAFEEIRO ARÁBICA SUBMETIDO AO DÉFICIT HÍDRICO
}

\author{
Anelisa de Figueiredo Peloso ${ }^{1}$ \\ Sandro Dan Tatagiba ${ }^{2}$ \\ Felipe Cassa Duarte Venâncio ${ }^{3}$ \\ José Francisco Teixeira do Amaral ${ }^{4}$
}

Resumo: O objetivo deste estudo foi investigar as respostas fotossintéticas em folhas de café arábica submetido ao déficit hídrico, utilizando para isso, os parâmetros de trocas gasosas da fotossíntese [assimilação líquida de CO2 (A), condutância estomática ( $g s)$, taxa de transpiração (E) e concentração interna de $\mathrm{CO} 2$ (Ci)], as concentrações de pigmentos cloroplastídicos e o extravasamento de eletrólitos (EE) em folhas de plantas cultivadas a 30, 60 e 100\% de água disponível (AD) no substrato. De acordo com os resultados obtidos foi verificado que os déficits hídricos afetaram negativamente a fotossíntese das plantas, ocasionando decréscimos significativos em gs, os quais, estiveram associados a diminuição nos valores de A. À medida que se intensificou o déficit hídrico foi encontrado redução nos teores das clorofilas e danos as membranas celulares.

Palavras-chave: Coffea arabica L.; Estresse hídrico; Pigmentos cloroplastídico; Trocas gasosas.

\footnotetext{
1 Departamento de Engenharia Rural/Universidade Federal do Espírito Santo, Brasil. E-mail: anelisapeloso@hotmail.com.

2 Departamento de Ciências Florestais e da Madeira/Universidade Federal do Espírito Santo, Brasil. E-mail: sandrodantatagiba@yahoo.com.br.

3 Departamento de Engenharia Rural/Universidade Federal do Espírito Santo, Brasil. E-mail: felipe.duarte22@hotmail.com.

4 Departamento de Engenharia Rural/Universidade Federal do Espírito Santo, Brasil. E-mail: jftamaral@yahoo.com.br.
} 